\title{
THE TEMPERATURE DISTRIBUTIONS OF BONE TUMOR THERAPY USING SCANNED FOCUSED ULTRASOUND SYSTEM \\ ${ }^{1,4}$ Bing-Yuh Lu, ${ }^{2}$ Win-Li Lin, ${ }^{3}$ Rong-Sen Yang, ${ }^{1}$ Yung-Yaw Chen, ${ }^{2}$ Cheng-Yi Wang, ${ }^{1} \mathrm{Te}-$ Son Kuo \\ ${ }^{1}$ Department of Electrical Engineering, ${ }^{2}$ Gratuate Institute of Biomedical Engineering, National Taiwan University \\ ${ }^{3}$ Department of Orthopedics, National Taiwan University Hospital, ${ }^{4}$ Department of Electronic Engineering, Tung-Nan Junior College of Technology \\ Taipei, Taiwan \\ E-mail:blu@roc.tnjc.edu.tw
}

\section{Abstract}

The temperature distributions of bone tumor therapy using scanned focused ultrasound hyperthermic system (SFUS) have been simulated. The power arrays in SFUS have been tilted, rotated, translated and convoluted to obtain the power distributions. The temperature distributions are calculated by 3-D Bio-heat Transfer Equation (BHTE). The simulation results reveal that the overheating on bone occurs when tilt angle and rotation angle decrease, but when scanning radius toward to tumor increases.

Keywords: bone tumor, temperature distribution, ultrasound therapy, hyperthermia

\section{Introduction}

Fan et al. [1] reported the preliminary report on treatment of bone tumors with microwave-induced hyperthermia. It is shown that to treat bone tumors using hyperthermia is an efficient therapy. Therefore, we use the SFUS to externally heat the bone tumor breaking out the long bone. We use the normalized tumor volume > $42{ }^{\circ} \mathrm{C}$ of tumor and normal tissue to evaluate the effect of different parameters of SFUS.

\section{Method}

The schematic of scanned focused ultrasound system for bone tumor is shown in Fig. 1. The diameter of bone (DB) is $3 \mathrm{~cm}$, the depth of muscle (DM) is $5 \mathrm{~cm}$, and the diameter of tumor is $1.5 \mathrm{~cm}$. The diameters of spherical transducers in the applicator of SFUS are all $5 \mathrm{~cm}$ with $10 \mathrm{~cm}$ radial curvature. The driving frequency of the transducers is $2.5 \mathrm{MHz}$. The temperature distributions are simulated by finite difference technique to calculate the steady-state bio-heat transfer equation (BHTE):

$\nabla \cdot(k \nabla T)+q-W_{b} C_{b}\left(T-T_{b}\right)=0$

$\mathrm{T}$ is the tissue temperature, in ${ }^{\circ} \mathrm{C}$. The $\mathrm{k}$ is the tissue thermal conductivity, in $\mathrm{W} /\left(\mathrm{m}^{\circ} \mathrm{C}\right)$; in soft tissue is $\mathbf{0 . 5 5}$ $\mathrm{W} /\left(\mathrm{m}^{\circ} \mathrm{C}\right)$, and in bone is $1.16 \mathrm{~W} /\left(\mathrm{m}^{\circ} \mathrm{C}\right) . \mathrm{W}_{\mathrm{b}}$ is the blood perfusion rate, in $\mathrm{kg} /\left(\mathrm{m}^{3} \mathrm{~s}\right)$, and in bone is assumed to be $0 \mathrm{~kg} /\left(\mathrm{m}^{3} \mathrm{~s}\right) . \mathrm{C}_{\mathrm{b}}$ is the blood specific heat, in $\mathrm{J} /\left(\mathrm{kg}^{\circ} \mathrm{C}\right)$; in soft tissue is $3770 \mathrm{~J} /\left(\mathrm{kg}^{\circ} \mathrm{C}\right) . \mathrm{T}_{\mathrm{b}}$ is the arterial blood temperature, in ${ }^{\circ} \mathrm{C}$; here is $37^{\circ} \mathrm{C}$. The $\mathrm{q}$ is the power applied via ultrasound, in $\mathrm{W} / \mathrm{m}^{3}$. All boundaries are treated as constant temperature $37^{\circ} \mathrm{C}$ boundary.

\section{Results}

To find the heating patterns associated with system parameters, we have the tilt angles to be $20,25,30,35$, 40 , and 45 degrees, rotation angles to be $0,30,60$, and 90 degrees, and scanning radii to be 0,5 , and $10 \mathrm{~mm}$. We find that the tilt angle is the dominant factor to influence the normalized tumor volume of tumor and normal tissue. The tilt angle of 35 to 45 degrees has almost $100 \%$ normalized tumor volume $>42{ }^{\circ} \mathrm{C}$ in tumor, but lower ratio of normalized tumor volume $>42$ ${ }^{\circ} \mathrm{C}$ in normal tissues (about 1 to 3 ).

\section{Discussions}

The simulation results reveal that the overheating on bone occurs when tilt angle and rotation angle decrease, but when scanning radius toward to tumor increases.

\section{Reference}

[1] Q. Y. Fan, B. A. Ma, X. C. Qiu, Y. L. Li, J. Ye, and Y. Zhou, "Preliminary report on treatment of bone tumors with microwave-induced hyperthermia," Bioelectromagnetics, vol. 17, pp. 218-222, 1996.

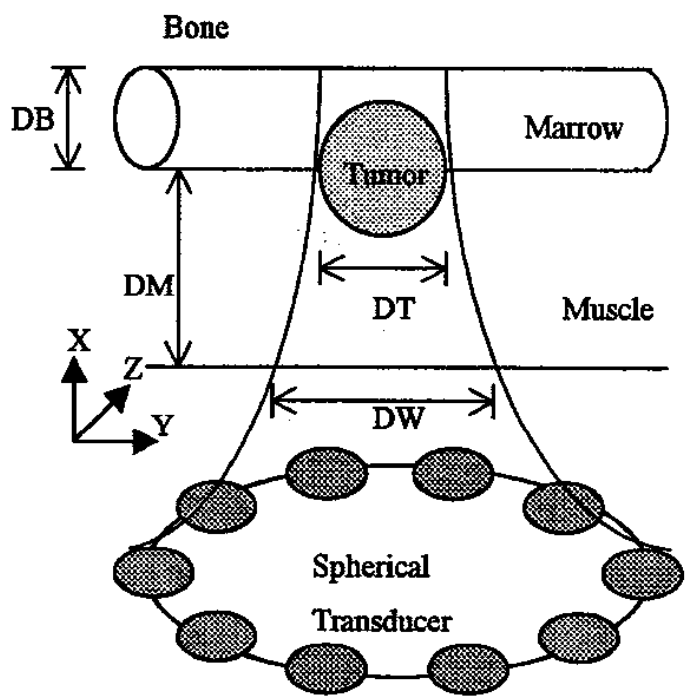

Fig. 1 The schematic of scanned focused ultrasound system for bone tumor 